\title{
Monitoring of underdeck corrosion by using acoustic emission method
}

Krzysztof Emilianowicz, M. Sc., Gdańsk University of Technology, Poland

\begin{abstract}
This paper presents first short characteristics of underdeck corrosion process as well as a problem of its monitoring. Next is described an acoustic emission (AE) method elaborated by Department of Ship Technology, Quality Systems and Material Engineering, Gdańsk University of Technology in cooperation with partners of CORFAT project realized within $7_{\text {th }}$ EU Frame Program. Further are presented short characteristics of the emission process, used measuring instrumentation of Vallen Systeme GmbH, as well as TESTER, corrosion testing device, and a corrosion solution used in the tests. Finally, results of the tests performed on selected marine units, are presented.

$1 * G U T$ - Gdańsk University of Technology

$2 * T \ddot{U} V-$ Austria

$3 *$ TESTER - a device used for simulation of corrosion processes without destruction of tested material surface.

$4 *$ Corrosive solution - a solution which catalizes corrosion processes in the tester $5 *$ SMW S.A.- Naval Shipyard Co.
\end{abstract}

Key words: underdeck corrosion; acoustic emission (AE); corrosion tester; marine units

\section{INTRODUCTION}

Underdeck corrosion - It is impossible to unambiguously define this notion as - depending on a place of its ocurring - it may be of a typical electrochemical, chemical or fatigue character. Usually it may be:

- pitting corrosion,

- fatigue corrosion,

- oxygen corrosion,

- microbiological corrosion.

The most obvious places of appearing corrosion wastage are tanks of any kind, e.g.:

- ballast tanks,

- fresh water tanks,

- tanks for crude oil and oil products,

- sewage tanks.

Also, it may happen in such places as e.g.: connections of decks,

- connections of underdeck stiffeners,

- connections of stiffeners with deck plating,

- drains from heat exchange devices.

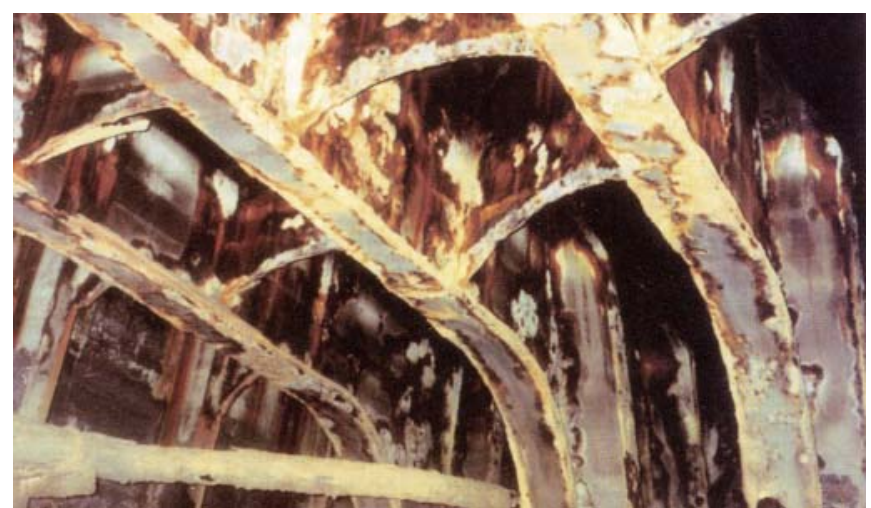

Fig. 1. An example of ship underdeck corrosion [5]

As results from the above given description this is a serious problem as the places exposed to such destruction are as a rule hardly accessible or non-accessible at all during ship (unit) service. The question hence arises: how to monitor the process?

This work has been aimed at presentation of a method which is enough promising and providing suffciently good results to make monitoring the process possible. 


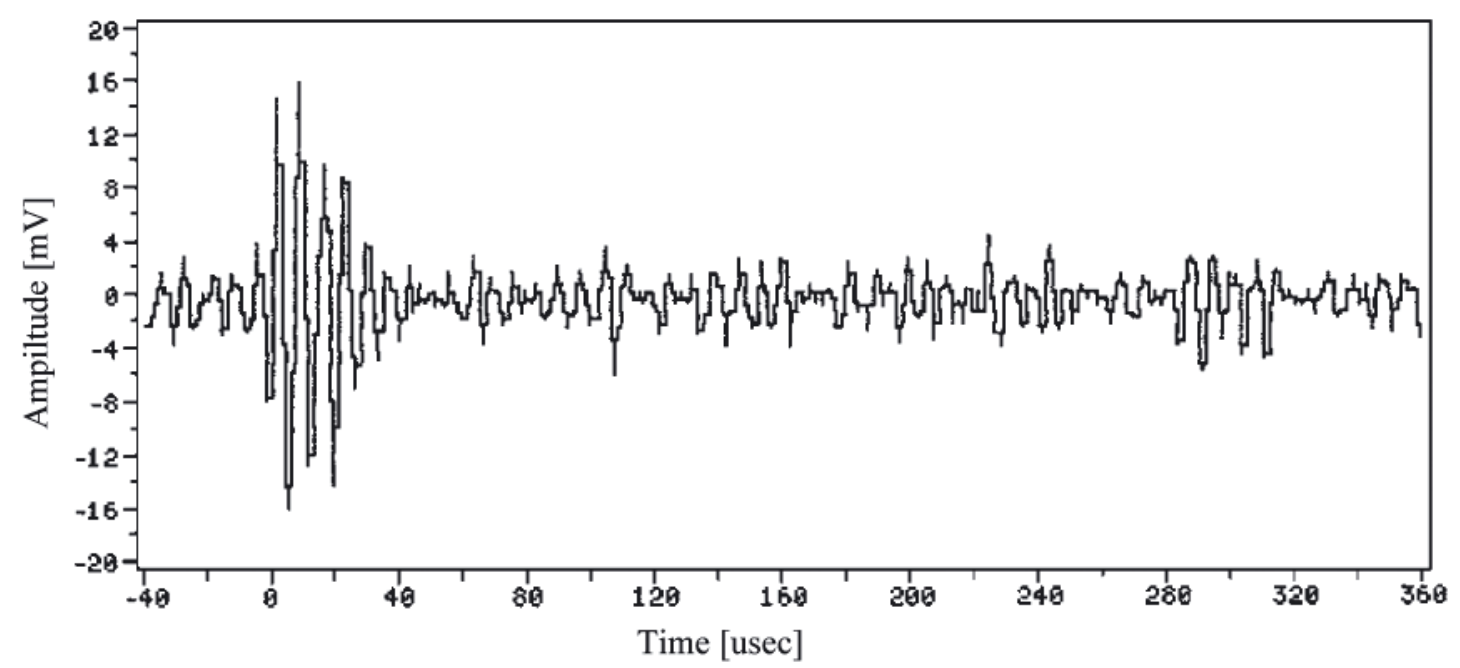

Fig. 2. Run of short wave [4]

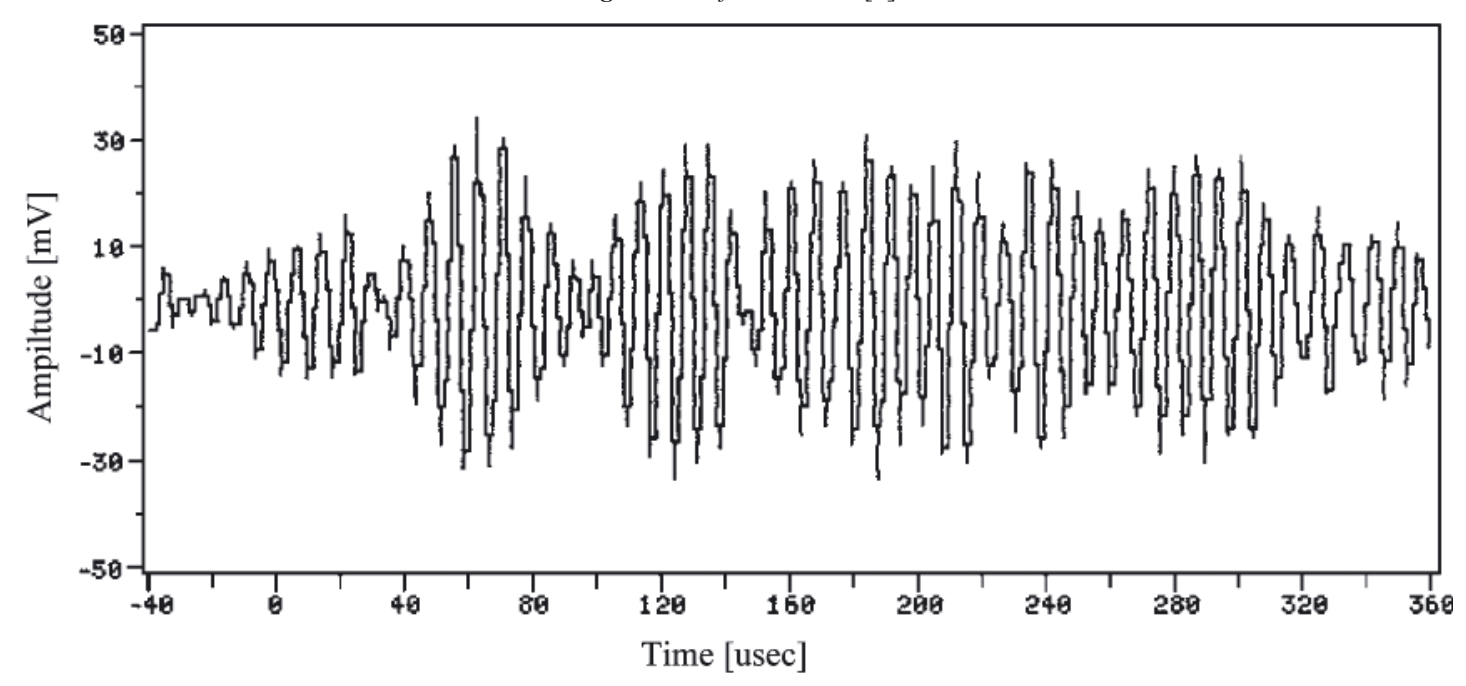

Fig. 3. Run of reflected wave [4]

\section{Historical outline}

The acoustic emission phenomenon was first implemented by Parry to test pitting corrosion inside a pipe. He observed that acoustic emission can be generated by different cracks resulting from oxygen depositions on surface of corrosion defects if only a stable hydrostatic pressure flow is exerted to the tested segment of pipe [9, 14]. In 1976 two scientists, Reting and Felsen, proved that the relationship between acoustic emission and amount of oxygen released from aluminium rods immersed in salt water, is linear. They also suggested that it is possible to test other physical chemical properties by means of acoustic emission [9, 14]. In 1976 Mansfeld and Stocker showed accurate relation between activity of acoustic events occurring in Al-alloys immersed in $3 \% \mathrm{NaCl}$ solution, and amount of pitting corrosion. While running the tests many acoustic signal fluctuations were observed during anodic polarisation $[9,14]$.

\section{Acoustic emission (AE) method}

Acoustic emission is formed by sound signals which accompany changes of material structure during violent release of internal energy stored in it. During transferring wave through material, in the case of its coming across a defect, dispersion and reflection of the wave occurs. The phenomenon is called acoustic event. During such event, occurs acoustic wave emission which results from released internal energy. The so formed wave (Fig. 2) is recorded by an acoustic sensor. Events which become sources of wave emission can be of a low-energy or high-energy character $[14,4]$.

\section{Criteria for determining acoustic emission}

In measuring and investigating acoustic emission, counting number of pulses or events or acoustic emission rate (number of events per time unit) is usually used as a measure of the phenomenon. For AE analysis to measure amplitude and duration of pulses lasting from a few micro-seconds to decimal parts of seconds, is necessary [4].

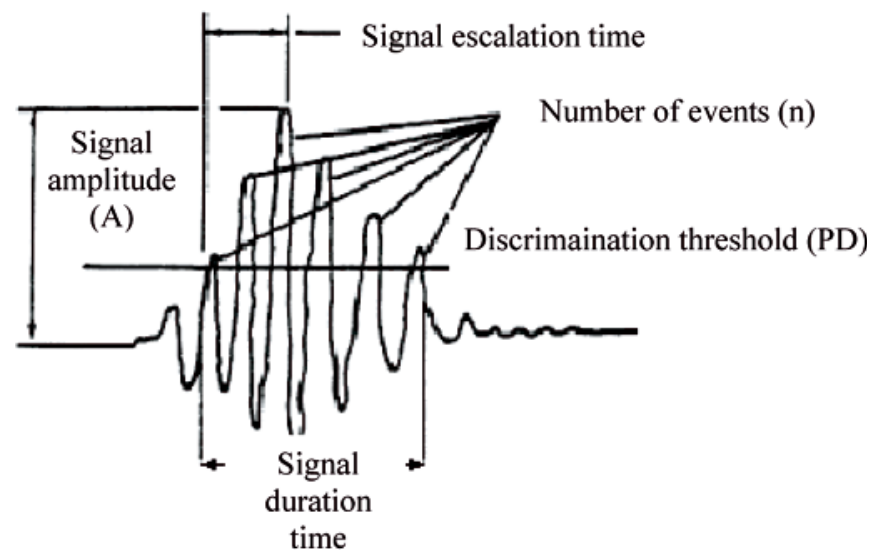

Fig. 4. A single acoustic emission signal [4, 14] 


\section{Advantages of AE method $[4,14]$}

Advantages of AE method are the following:

- possible continuous performing investigations,

- possible monitoring defect initiation place and time,

- possible testing large structures,

- owing to a large number of acoustic sensors, to precisely locate signal source, thus to determine place of defect occurrence, is possible.

The AE method is one of the non-destructive testing methods (NDT) and found wide application in the following areas of corrosion monitoring and - first of all - to assessing consequences of corrosion processes:

- analyzing and detecting corrosion cracks,

- testing corrosion in steel rods of reinforced concrete structures,

- detecting cracks of any kind and leakages from piping and tanks,

- testing degradation of laminates and linings [14].

\section{Acoustic wave sensors $[14]$}

Sensor is a device for transforming chemical, biolgical or physical stimulus coming from external environment, into electric signal which is a function of the output signal [14].

Acoustic sensors are divided, depending on a way of execution of measurements, into the following kinds:

- capacity ones,

- piezoelectric ones,

- electro-dynamic ones,

- nterferometric ones.

During the tests described in Ch. 3 piezoelectric acoustic sensors of $20 \div 80 \mathrm{kHz}$ frequency range were used for monitoring corrosion and corrosion - fatigue processes.

\section{METHOD OF VERIFYING THE ASSSUMED AIM}

The method elaborated by the Department of Ship Technology, Quality Systems and Material Engineering in the frames of CORFAT project realized within $7^{\text {th }}$ EU Frame Program, takes into account interaction of the three elements:

- the Vallen AMSY-5 measuring system together with sensors,

- the corrosion tester,

- the corrosive solution.

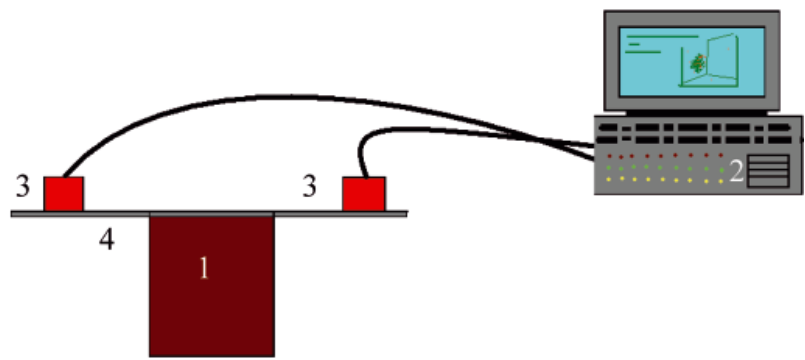

Fig. 5. Schematic diagram of the system used for underdeck corrosion measurements: 1) corrosion tester; 2) Valen AMSY-5 measuring system; 3) measurement sensors; 4) ship's deck

\section{AMSY-5 measuring system}

For recording AE signals and their analysis a specialty software of Vallen Systeme GmbH was used, namely:

- Visual AE,

- Visual TR,

- Visual Class.

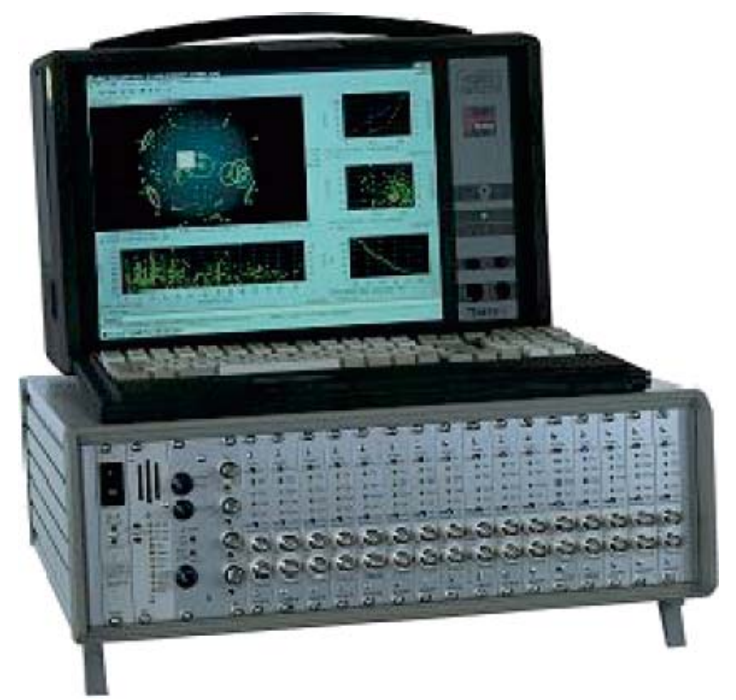

Fig. 6. AMSY-5 system of Vallen Systeme GmbH for AE testing [2]

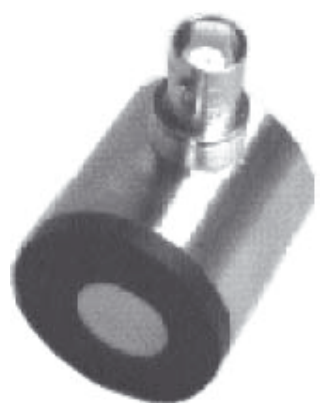

Fig. 7. VS 150-RIC measurement sensor of Vallen Systeme GmbH [2]

\section{Corrosion tester}

In the tests corrosion testers were used as AE sources since they make it possible to simulate corrosion without any destructive influence on the tested material of ship structure.

Which are criteria for selecting such tester?

Tester is to be built in such a way as to simulate most credibly conditions existing in a given place under testing, hence, the following items are to be appropriately selected:

a) size of the tester;

b) material for the tester, which should be the same or close to that to be tested;

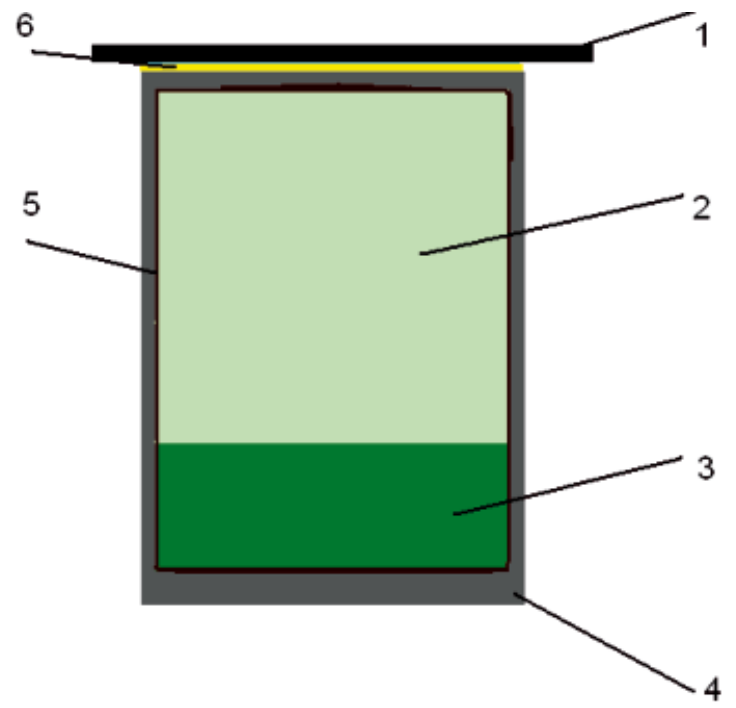

Fig. 8. Schematic diagram of corrosion tester: 1) ship's deck; 2) corrosive gas; 3) corrosive solution; 4) tester's reaction cylinder; 5) initiated corrosion; 6) acoustic contact 
Possible mounting positions of KE-02GUT corrosion tester

a)

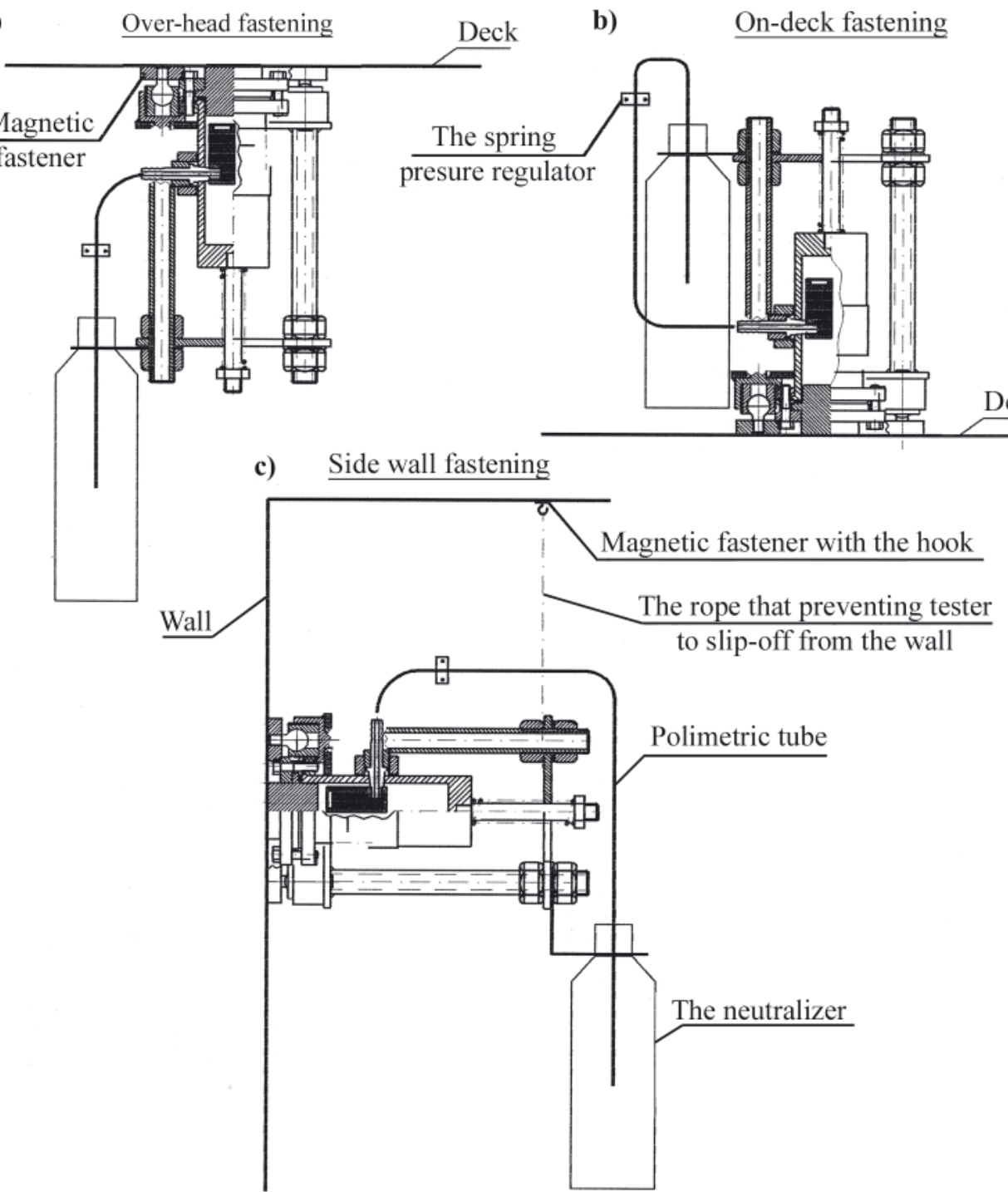

Fig. 9. Schematic diagram presenting possible positions of KE-02(GUT) corrosion tester against ship's deck: a) over-head fastening, b) on-deck fastening, c) side wall fastening

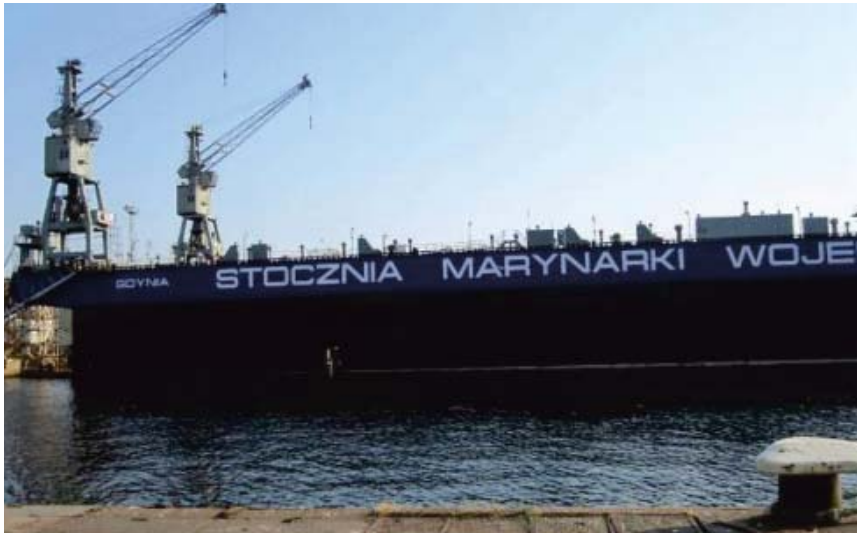

Fig. 10. Naval Shipyard Co floating dock of $135 \mathrm{~m}$ in length, and $35 \mathrm{~m}$ in breadth

c) surface area of contact of the tester with the tested surface, which should be sufficiently large as to correctly transfer acoustic signal, that is equivalent to tester's detectability;

d) corrosive solution.

The tester is fastened to a tested surface by means of magnetic fasteners but a way of fastening or image of corrosion cylinder depends on a type of tester.

\section{RESULTS OF THE TESTS}

The presented measurements were aimed at the following: - detection of signals generated by active corrosion sources, by using the existing AE signal classificator,

- collection of data base on background noise coming from: operation of main and auxiliary electric generating sets, main engines, performed welding work etc, which will make it possible to elaborate a better version of AE classificator and improve this way detection quality of signal coming from active corrosion sources as well as corrosion fatigue defects.

\section{Place of the tests performed on Naval Shipyard Co floating dock}

The tank No. 11 7,95 $\mathrm{m}$ long and 4,7 $\mathrm{m}$ broad was the object in which the tests in question were performed. The test was performed for both two measurement conditions:

- dry tank,

- tank filled with sea water up to l' of its height.

The applied measuring instrumentation consited of:

- EA AMSY-5 Vallen system,

- VS75 and VS-150 RIC sensors as well as novel ISAS3 Vallen ones, 
TOP VIEW ON THE TANK NO. 11

Fatigue Tester (GUT)

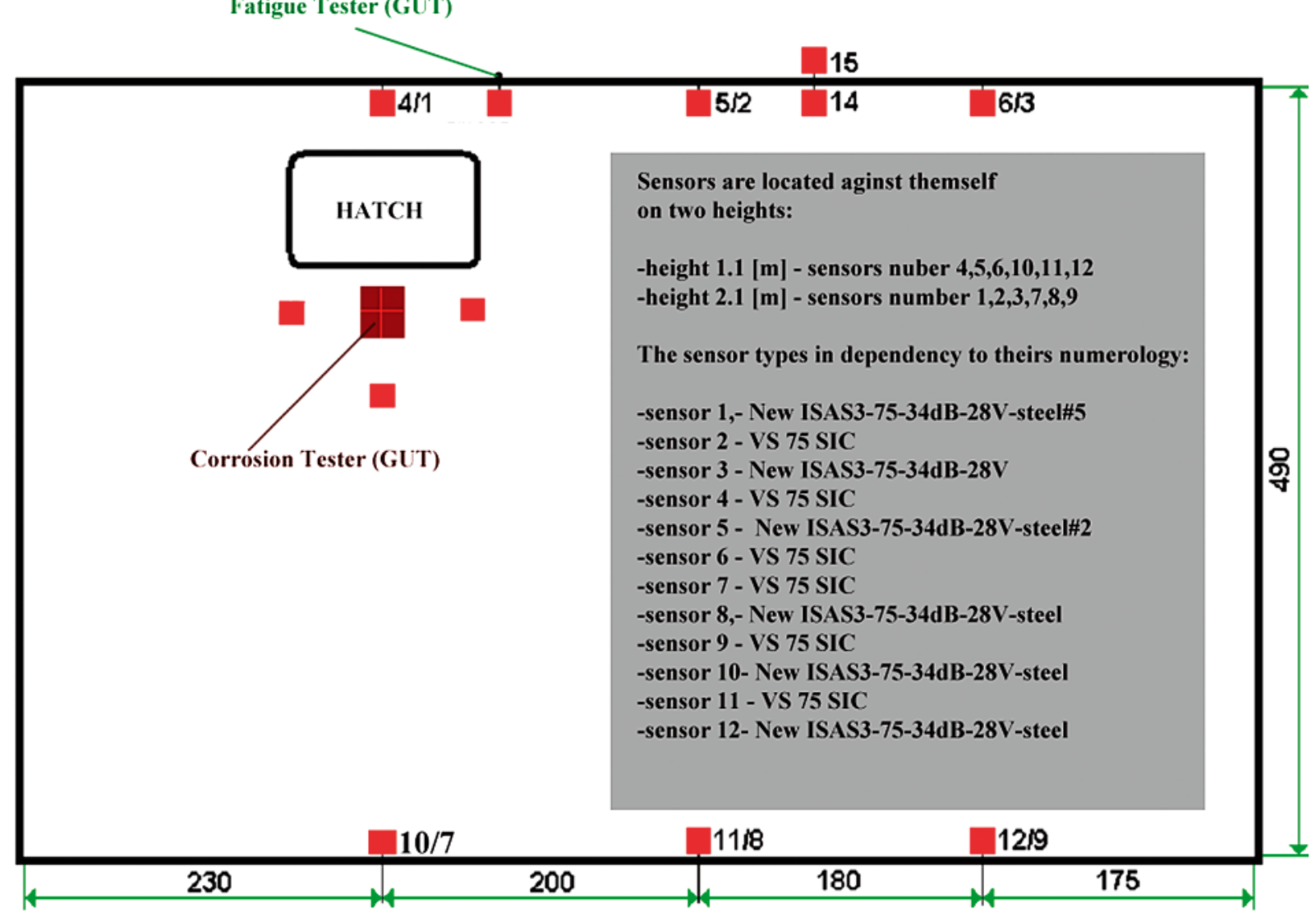

Fig. 11. Schematic diagram of arrangement of sensors and corrosion testers inside the tank No. 11 of the Naval Shipyard Co floating dock

- for calibration HSU $0.5 \mathrm{~mm}$ sensor and internal AMSY-5 system was used,

- the GUT and TÜV-Austria corrosion testers were implemented to serve as sources of AE corrosion signals,

- for fastening the sensors magnetic fasteners were used.

The corrosive solution of TÜV-Austria $\left(4.13 \mathrm{~L} \mathrm{H}_{2} 0,0.18 \mathrm{~L}\right.$ $68 \% \mathrm{HNO}_{3}, 0.18 \mathrm{~L} 98 \% \mathrm{H}_{2} \mathrm{SO}_{4} 0.14 \mathrm{~kg} \mathrm{NaCl}$ ) was applied.

Prior to measurements, paint coating was locally removed from plate surface and then the sensors and testers were fixed in this place. The entity was connected together by means of an acoustic silicone interface. Thickness of the plate was equal to about $10 \mathrm{~mm}$.

The corrosion tester was placed overhead on tanktop internal surface, about $100 \mathrm{~mm}$ from a manhole; additional AE sensors (measuring signal coming directly from the GUT

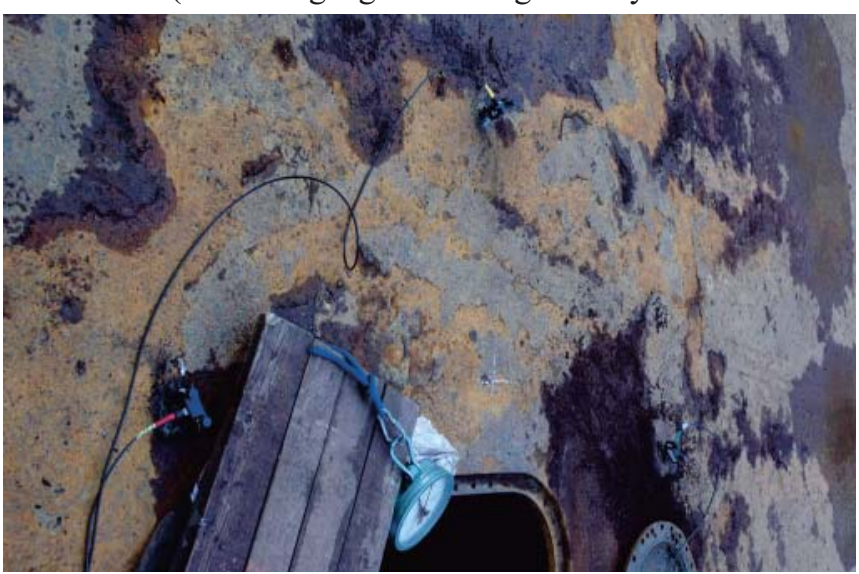

Fig. 12. View of the deck in the vicinity of the tank No. 11 of the Naval Shipyard Co floating dock tester) were located on external surface, about $300 \mathrm{~mm}$ from corrosion source, directly over the tester.

\section{Results of the tests performed on the Naval Shipyard Co floating dock}

Because of some technical problems as well as dificult weather conditions (air temperature close to $0^{\circ} \mathrm{C}$ resulting in a drop of rate of corrosion processes, strong wind disturbing measurements) all the tests with the use of the GUT tester, TUV corrosion testers and GUT fatigue tester, did not bring expected results. But it was managed to record and collect measurement data on background noise generated by welding and repair work carried out on the Naval Shipyard Co dock, that will be helpful for building a background noise data base for signal classificator in a further project.

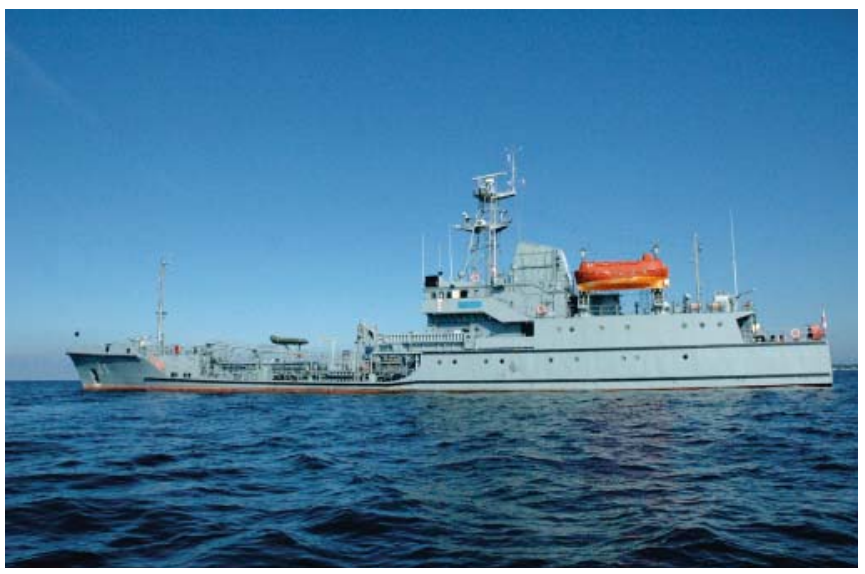

Fig. 13. View of the Polish Navy tanker ,Baltyk” 


\section{Place of the tests performed on the Polish Navy tanker „Baltyk”}

The next place of the tests was the tank V12 of cofferdam on the Polish Navy tanker „Bałtyk”. On the contrary to the earlier tests it was not allowed to locally remove paint coating, that was however taken into account during measurements. Also, no data on paint coating thickness were available because it was impossible to get access to painting documentation of the ship. Thickness of the plate was equal to about $6 \mathrm{~mm}$.

The tests were performed for two variants of measurement conditions:

a) during standstill of the ship (at a low activity of onboard equipment)

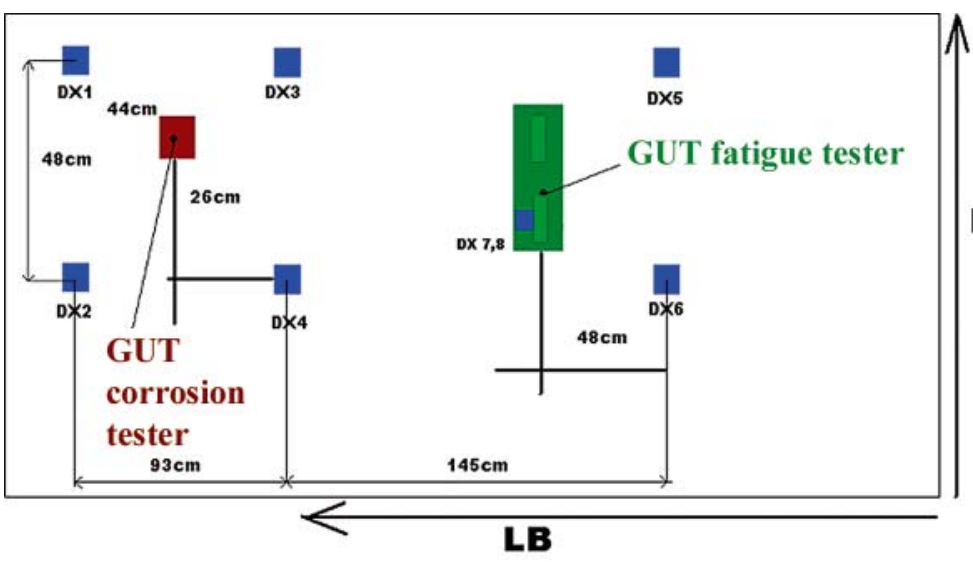

b) durin voyage of the ship (at regular operation of onboard equipment).

Instrumentation used for the tests:

- Vallen AMSY-5 system fitted with ASIP2 filters

- $\quad$ Novel ISAS 3 sensors

- VS-75 and VS-150 RIC sensors

- GUT tester used as a corrosion source

Both the sensors and testers were fastened on the tank walls by means of the magnetic fasteners. GUT - Gdansk corrosive solution $\left(2 \mathrm{~L} \mathrm{H}_{2} 0,0.3 \mathrm{~L} 68 \% \mathrm{HNO}_{3}, 0.25 \mathrm{~L} 98 \% \mathrm{H}_{2} \mathrm{SO}_{4} 0.07 \mathrm{~kg}\right.$ $\mathrm{NaCl})$ was applied.

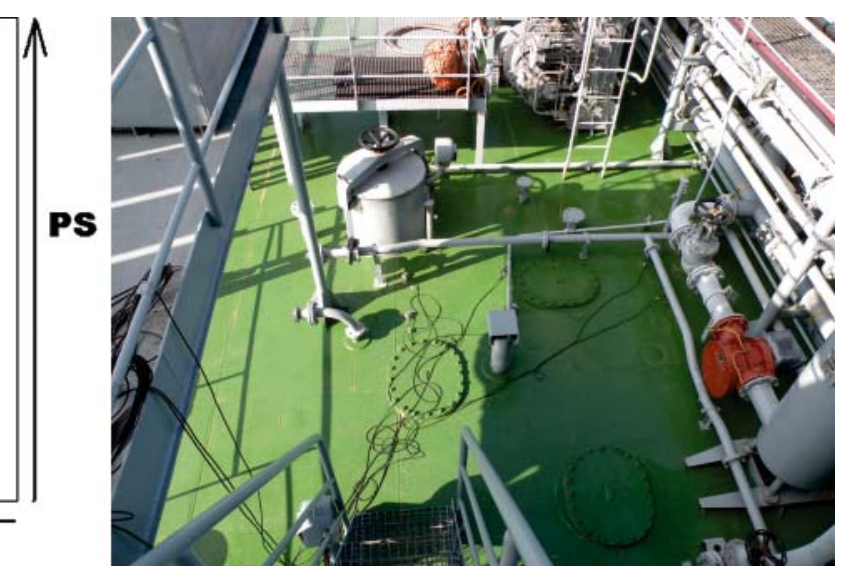

Fig. 14. Location of the test site (the tank No. V12 of cofferdam) and arrangement plan of the sensors on the deck of the Polish Navy tanker „,Baltyk”

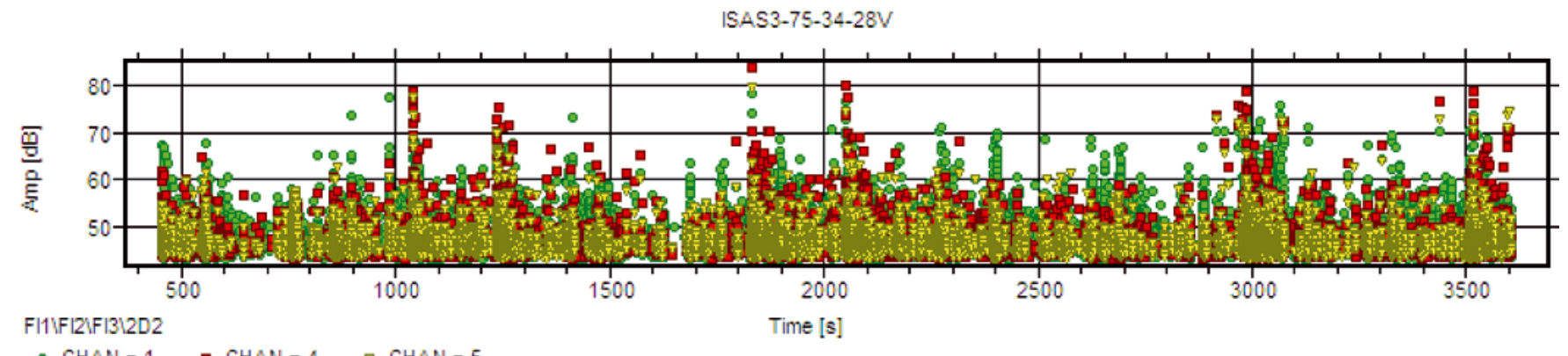

- $C H A N=1$ - $\mathrm{CHAN}=4 \quad$ $\mathrm{CHAN}=5$

ISAS3-75-34-28V

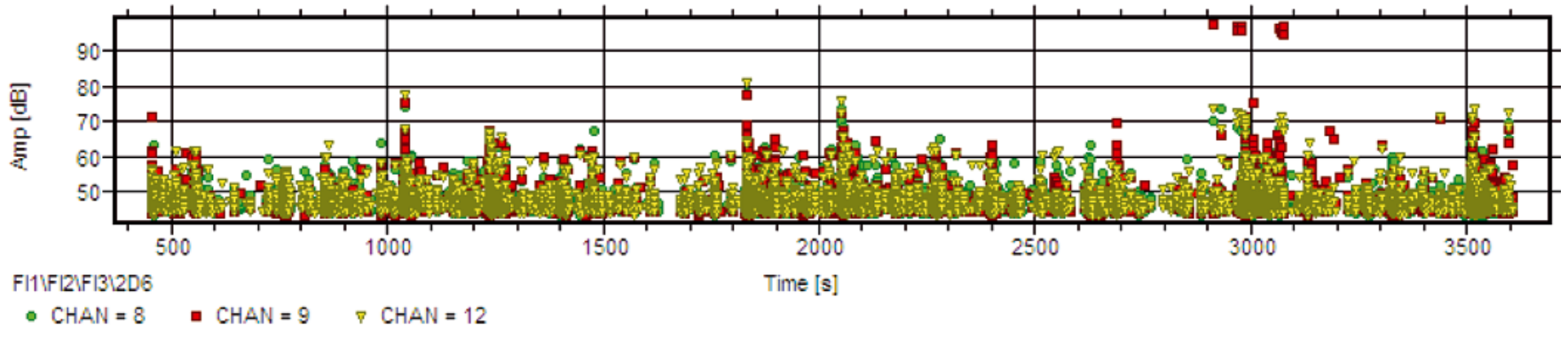

VS75V

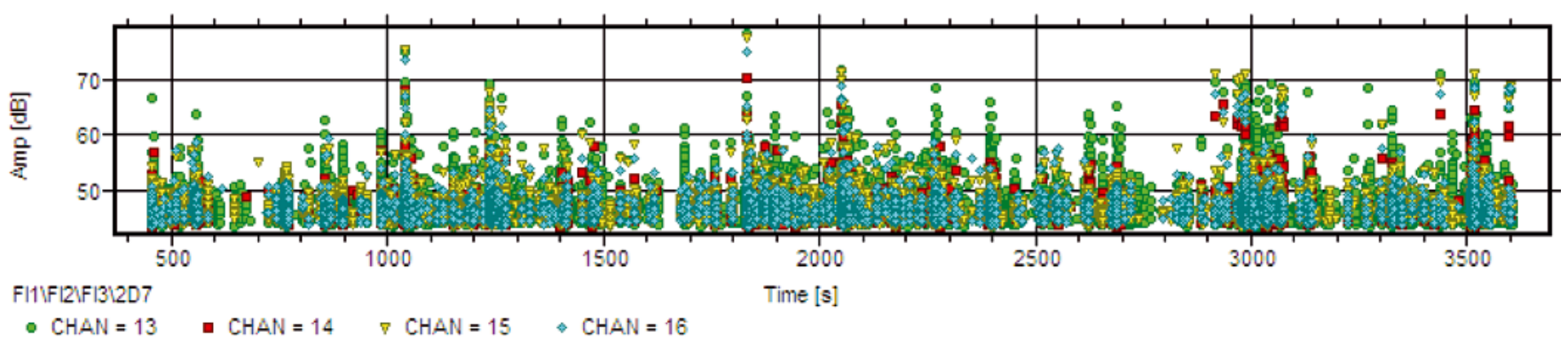

Fig. 15. Standstill test; records of external noise - AE signal amplitude for all measurement signals. $T h=43 d B$ 


\section{Results of the tests performed on the Polish Navy tanker „Baltyk”}

The tests were performed for two measurement conditions:

a) During ship's laying at anchor, at minimum number of ship's systems under operation, when the signal coming from the corrosion tester was so strong that it was possible to locate it. Results for the first testing conditions are presented in Fig. 15 and 16.

b) During sea voyage with the ship's systems under operation (main engines etc), when the signal coming from the corrosion tester, however weaker, was possible to be located due to application of a set of filters, e.g. frequency ones. Results for the second testing conditions are presented in Fig. 17 and 18.

Simultaneously, were performed the tests with the use of GUT fatigue tester, whose presentation was ommitted in this paper as they were beyond the scope of this author's work and whose realization did not influence detection quality of $\mathrm{AE}$ signal coming from the GUT corrosion tester.

\section{SUMMARY}

The described AE method shows many adventages in relation to other non-destructive testing methods, namely:

- speed of measurements,

- effectiveness of corrosion signal detection,

- repeatability,

- detection possible even at one -side access.

From the above described measurements results that $\mathrm{AE}$ signals coming from the corrosion tester can be detected both in the tanks with paint-coating and without it.

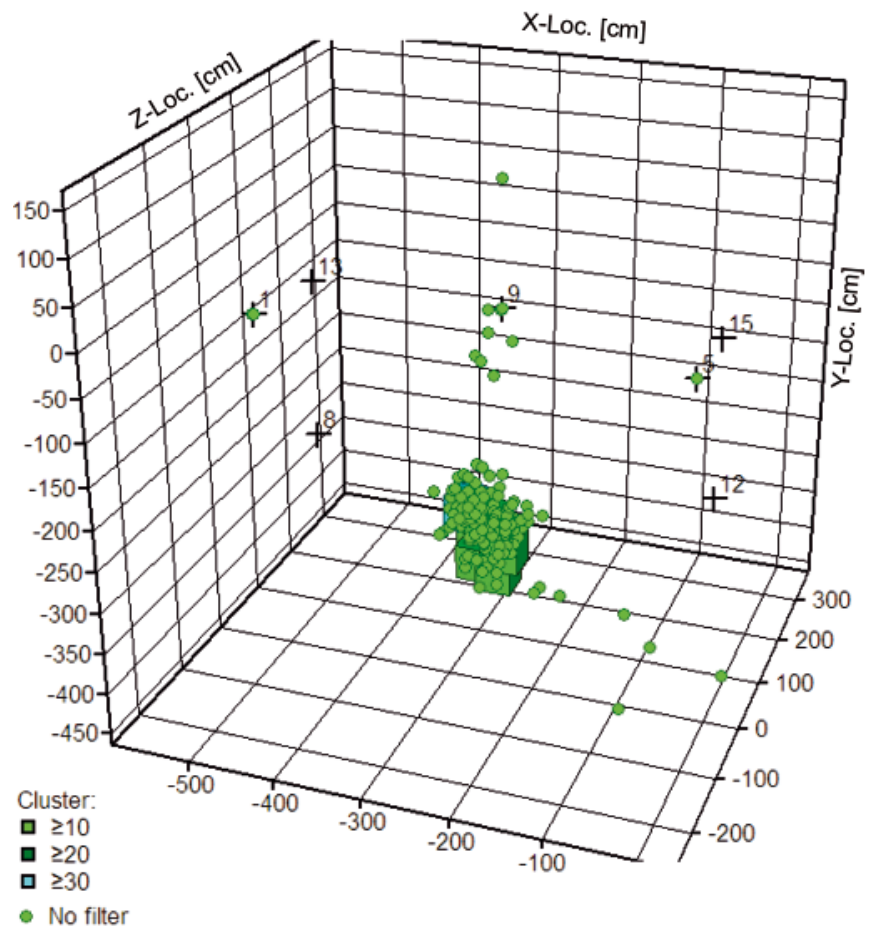

Fig. 16. Standstill test; 3-D location of corrosion source (the tester) close to DX4sensor:Th $=43 \mathrm{~dB}$

However, results of the tests may be influenced by various factors such as: atmospheric conditions, ambient temperature and energy and intensity of external noise (e.g. operation of engines). They can make locating and identifying AE signals coming from active corrosion sources, difficult. In many cases it is possible, despite the unfavourable factors, to separate signals

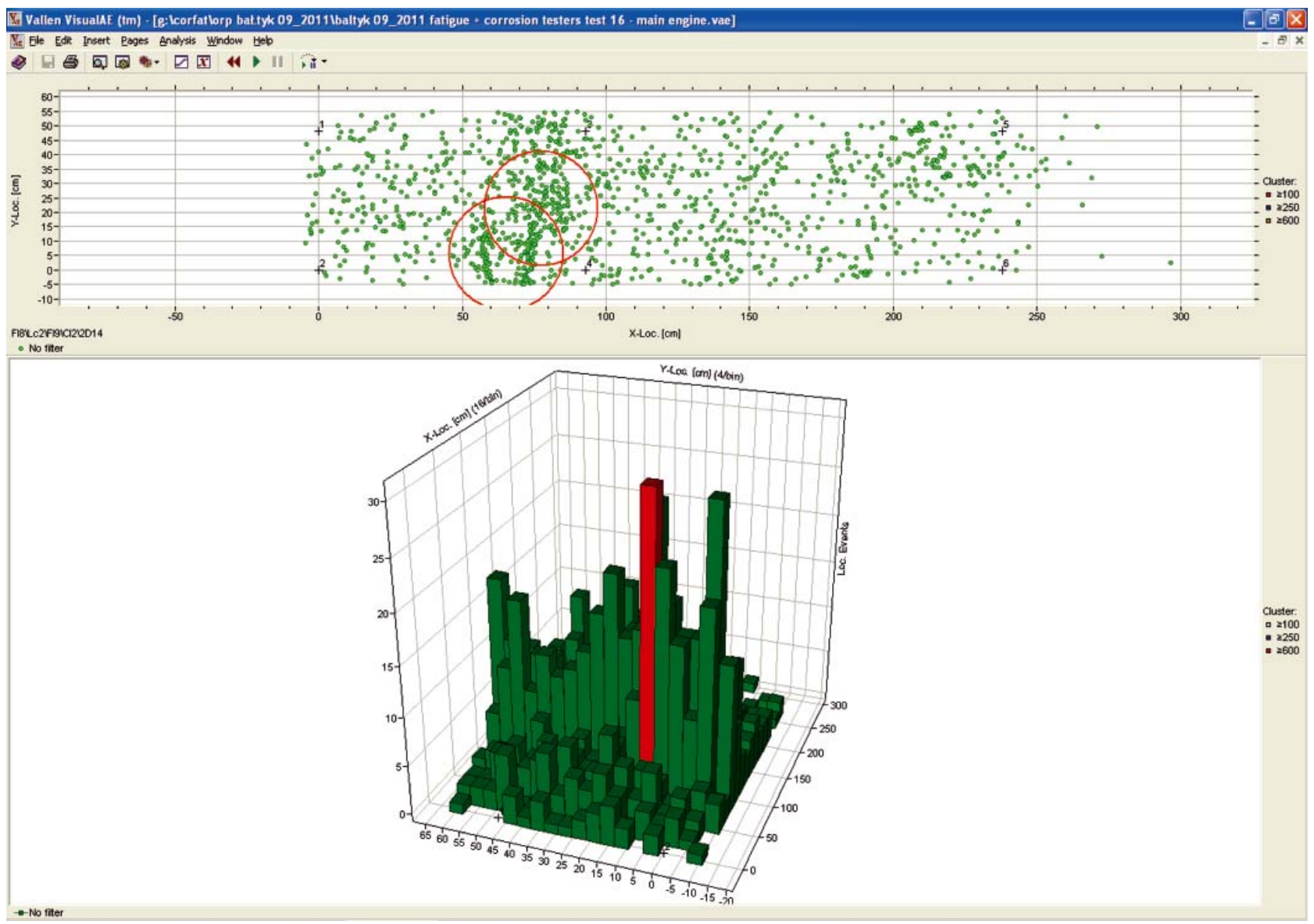

Fig. 17. Location of the corrosion tester and partial location of the tester during operation of engines 


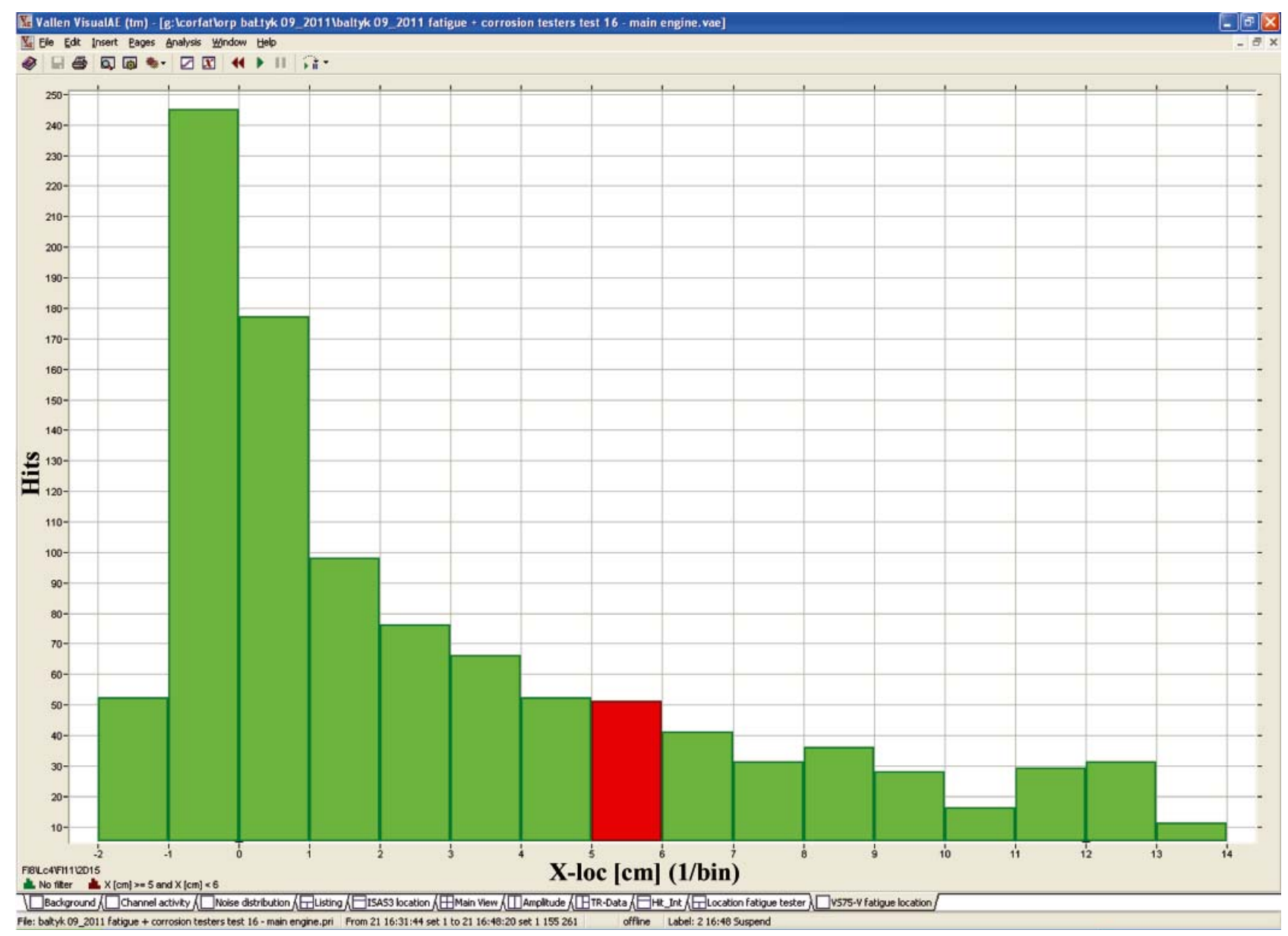

Fig. 18. Diagram of output from ISAS3 sensor - signal coming from the corrosion tester during operation of engines

out of the background; however in some cases their detection is completely impossible, that produces difficulties in applying the method in question.

Note

The tests were performed in the frame of CORFAT project (Contract No. SCP7-GA-2008-218637 - Cost effective corrosion and fatigue monitoring for transport products) realized within $7^{\text {th }}$ EU Frame Program.

\section{BIBLIOGRAPHY}

1. TÜV Austria: Corrosion testing of ships. Project of V FPEU "CORRSHIP". Contract EVG1-CT-2002-00067, 2003 $\div 2006$.

2. Vallen Systeme GmbH: AMSY-5 Specification. The Acoustic Emission Company. Icking Germany.

3. PN-EN 1330-9: 2002 Polish standard: Non-destructive tests - Terminology - Part 9: Terms applicable to acoustic emission tests (in Polish), 2002.

4. Malecki I., Ranachowski J. (Editors): Acoustic emission. Sources. Methods. Applications (in Polish). PAN IPPT, Warszawa 1994.

5. TÜV Austria: Cost effective corrosion and fatigue monitoring for transport products. Project of $7^{\text {th }}$ FPEU "CORFAT". Contract SCP7-GA-2008-218637. TÜV Austria 2008.

6. Tscheliesnig P.: Corrosion testing of ship building materials with acoustic emission. In Proceedings of EWGAE 2004 Conference.

7. Assouli B., et al.: Detection and identification of concrete cracking during corrosion of reinforced concrete by acoustic emission coupled to the electrochemical techniques NDT\&E International 38, pp. 682-689, 2005.

8. Bellenger F., et al.: Use of acoustic emission for the early detection of aluminum alloys exfoliation corrosion NDT\&E International 35, pp. 385-392, 2002.
9. Fregonse M., et al.: Initiation and propagation steps in pitting corrosionof austenitic stainless steels: monitoring by acoustic emission Corrosion Science 43, pp. 627-641, 2001.

10.Fregonse M., et al.: Monitoring pitting corrosion of AISI 316L austenitic stainless steels by aocuistic emission technique: Choice of representative acousitc parameters Journal of Materials Science 36, pp. 557-563, 2001.

11.Kim Y. P., et al.: Ability of acoustic emission technique for detecting and monitoring of cravice corrosion on $304 \mathrm{~L}$ austenitic stainless steels NDT\&E International 36, pp. 553-562, 2003.

12.Mazille H., et al.: An acoustic emission technique for monitoring pitting corrosion of austenitic stainless steels Corrosion Science, Vol. 37, No 9, pp. 1365-1375, 1995.

13.Assouli B., et al.: Characterization and control of selective corrosion of $\alpha, \beta$ '-brass by acoustic emission NDT\&E International 36, pp. 117-126, 2003.

14.Emilianowicz K.: Electrochemical and acoustic tetsts of 5754 alloy in presence of corrosion inhibitor (in Polish). M.Sc thesis, Chemistry Dept., Gdansk University of Technology, Gdańsk 2008 .

\section{CONTACT WITH AUTHOR}

Krzysztof Emilianowicz, M. Sc. Faculty of Ocean Engineering and Ship Technology,

Gdańsk University of Technology

Narutowicza 11/12

80-233 Gdańsk, POLAND 